\title{
The Nasal Discharge in Leprosy: Clinical and Bacteriological Aspects
}

\author{
T. F. DAVEY \\ LEPRA, 50 Fitzroy Street, London W1P $6 A L$ \\ and
}

R. J. W. REES

National Institute for Medical Research, Mill Hill, London NW7 IAA

Nasal discharges containing acid-fast bacilli were studied broadly, in India, in relation to their clinical setting in 363 patients, and intensively, in London, in relation to their bacteriology.

The rarity of such a nasal discharge in borderline leprosy was in striking contrast to its frequency in untreated lepromatous leprosy. In this series the nasal discharge did not develop gradually with the advance of lepromatous leprosy. Highly bacilliferous discharges were encountered in early lepromatous leprosy, indicating nasal involvement far more severe than external appearances suggested. At a later stage the bacteriological importance of the discharge waned, but became once again of great significance with the onset of recrudescence.

The typical nasal discharge is an inflammatory exudate rich in both Myco. leprae and macrophages displaying every stage in globus development. The exceptionally high B.I. and high M.I. of ten encountered in untreated patients in this series frequently exceeded the highest values found in skin. The nasal discharge was encouraged by moist atmospheric conditions and diminished rapidly with even small doses of dapsone.

Fresh early morning specimens and $24 \mathrm{~h}$ collections of nasal discharges from 31 patients in this series were sent on wet ice to London, together with fresh biopsies of highly infected skin from 11 of these patients.

Bacillary isolates from the nasal discharges of all 31 patients produced growth curves in the mouse footpad characteristic for Myco. leprae, indisputable proof that this organism was present in every case. The mean total yield of acid-fast bacilli in $24 \mathrm{~h}$ collections was $2.4 \times 10^{8}$, with a morphological index of 12.8 . Single nose-blow collections showed a mean discharge of $1.1 \times 10^{8}$ acid-fast bacilli with a mean morphological index of 16.9. Comparison between the content of acid-fast bacilli/g of skin and that of the specimen of nasal discharge from the same patient showed a significantly higher proportion of solidly staining bacilli in the nasal discharge.

In 3 patients, mouse inoculation tests for dapsone sensitivity of Myco. leprae isolated from nasal discharges and skin biopsies revealed dapsone resistant bacilli both in the skin and in the nasal discharge.

The capacity of Myco.leprae in nasal discharge to survive outside the body was tested in 3 cases, by allowing the discharge to dry in the dark, at room temperature, and sampling for mouse inoculation being undertaken at $1,1.75,3,7$, and 10 days. Full survival was found after $24 \mathrm{~h}$, and $10 \%$ after 1.75 days, but none after 3,7 and 10 days, except in 1 sample in which some growth occurred after 7 days.

Similarities with tuberculosis, and the significance of both clinical and - bacteriological findings to the transmission of leprosy are discussed. 


\section{Introduction}

Very soon after the discovery of Mycobacterium leprae, it was recognized that what we now call lepromatous leprosy was associated with a nasal discharge containing acid-fast bacilli, sometimes in large numbers, and that this phenomenon can occur early in the disease. Gerber (1901), Jeanselme and Laurens (1897), Sticker (1897), and Klingmuller (1897) all drew attention to this. Schäffer (1898) went further, and demonstrated that large numbers of acid-fast bacilli could be projected in coughing, sneezing, and in normal speech, up to a distance of $1.5 \mathrm{~m}$ and beyond, in one case 185,000 bacilli in $10 \mathrm{~min}$. The importance of the nasal discharge as a possible source of infection to others was emphasised by Schäffer (1897), Sticker (1897), Jeanselme (1897), Muir (1929), and Rogers and Muir (1946).

There was no proof that bacilli discharged from the nose were in fact viable Myco. leprae, and no way of assessing their viability. This and other factors combined to diminish interest in the nose in leprosy, and a generation of neglect followed. In 1961, Shepard examined nasal washings from 4 patients with lepromatous leprosy, and using new techniques, proved that the bacilli concerned were in fact Myco. leprae, that at least some were viable, and that total numbers involved were very great, $10^{7}$ in 1 patient. The bacilli concerned had not been discharged by a natural process. Pedley, however $(1970,1973 a, b)$, found large numbers of bacilli morphologically identical with Myco. leprae in natural discharge from the nose of patients with lepromatous leprosy in Nepal, in contrast with almost negative findings in contact smears from unbroken skin in the same patients.

These findings pose fundamental questions. Is this bacillary laden discharge a general attribute of lepromatous leprosy? If not, which patients are implicated, and who most seriously? Are the bacilli discharged in fact Myco. leprae? If so, what numbers of viable Myco. leprae are involved? At what stage does a bacteriologically positive nasal discharge develop, how persistent is it, and how is it affected by chemotherapy? What is its relation to the pathology of the nose in leprosy? Finally, what happens to the bacilli after they have been discharged?

Here we report the findings of an extensive clinical study of patients with bacilliferous nasal discharges, attending for the first time at the Victoria Hospital, Dichpalli, Central India, combined with a quantitative bacteriological investigation of the discharge from some of these patients, undertaken at the National Institute for Medical Research, London. Conditions were unusually favourable for such a study, both from the angle of the clinical material available, and the speed with which fresh discharges could be transmitted to London. This work was the first stage in a wider clinical, histopathological and bacteriological study which is still in progress, and initial findings of which were reported at the Tenth International Leprosy Congress, Bergen, 1973, by Davey and Rees (1973); and Barton et al. (1973).

\section{Definition and Method}

This study is limited to the nasal discharge itself. Nasal smears were a separate issue, not dealt with here.

During the 9 months September 1971 to March 1972 and July - August 1972, all patients with lepromatous (LL,L1) or borderline leprosy on the lepromatous 
side (BL), attending for the first time, or after an absence of at least two years, were invited to blow their noses into new plastic bags on arrival, simultaneously with the routine bacteriological examination of multiple skin sites. Any discharge obtained was then smeared and examined for Myco. leprae in the usual way by a single observer (TFD), cell content also being observed. In dry weather, if patients complained of a discharge, but found it difficult to produce a specimen because of hard crusting in the nose, a gentle spray with distilled water, using an atomiser, assisted the process. Patients with indeterminate, tuberculoid, or borderline leprosy on the tuberculoid side were not included in this study.

Patients with highly bacilliferous discharges were admitted for more detailed observation and care, where agreeable, for periods up to 12 months. In selected individuals, records and smears of the discharge were made daily. Individual samples and $24 \mathrm{~h}$ specimens from selected patients were sent on ice to London, arriving within $30-54 \mathrm{~h}$ of production.

\section{Clinical Studies}

\section{PREV ALENCE OF NASAL DISCHARGES CONTAINING MYCO. LEPRAE}

During the 9 months under review, 936 patients came to the hospital for the first time, or in a few cases after an absence of more than two years, presenting either with lepromatous or borderline leprosy on the lepromatous side, all with skin smears positive for Myco. leprae. Of these 936 patients, 407 were able to profer a nose-blow on arrival. The specimens produced included discharges from coryza and other catarrhal conditions, but 363 of them were found to contain acid-fast bacilli identical in all respects with $M y c o$. leprae, an overall prevalence of $39 \%$.

Four reasons may be given for believing this to be too low a figure for the actual prevalence of bacteriologically positive nasal discharges among these patients.

(1) It is the universal custom in India for people to clear their noses as part of their early morning ablutions. What we were observing in almost every case was in fact a second specimen produced later in the morning. The ability to produce this was clearly indicative of an active, established pathological condition, and in the early and late stages of their disease some patients could not always oblige.

(2) The exudate, especially in dry weather, and in the early and late stages, often solidifies into hard crusts which can be both large and adherent, and render the clearing of the nose very difficult. Patients were encountered, not inf requently, who were able to clear their nose only at irregular intervals, with the production of a considerable amount of hard material. The day of arrival may not have coincided with such an occasion.

(3) The discharge is speedily and grossly altered as a result of even a short period of chemotherapy. Some patients on arrival were loath to admit that they had already taken some dapsone. The suspicion of this, aroused when bacilli in the discharge were found to have a morphological index of zero or near zero, led to our instituting urine tests for sulphone as routine. This proved very useful, and revealed this important source of fallacy.

(4) Finally, the human factor cannot be ignored. Some patients who could have produced a specimen were in too psychologically disturbed a condition to cooperate immediately, and it was not always possible to devote the time and 
attention necessary to encourage a patient to expose to other people what was to him the terrifying state of affairs in his nose.

Thus, 39\% is an exceedingly conservative figure for the prevalence of nasal discharges containing Myco. leprae in this large series of patients.

\section{TYPE AND STAGE OF LEPROSY IN RELATION TO NASAL DISCHARGE}

An analysis of the findings in relation to type and stage of leprosy is given in Table 1.

In Table 2, the bacteriological findings in nose-blows are compared with those in routine skin smears taken simultaneously.

TABLE 1

Prevalence of nasal discharges containing Myco. leprae

\begin{tabular}{lccccc}
\hline Clinical group & $\begin{array}{c}\text { Total } \\
\text { patients }\end{array}$ & \multicolumn{2}{c}{$\begin{array}{c}\text { No. with nasal } \\
\text { discharge ctn.AFB. } \\
\text { Total }\end{array}$} & $\begin{array}{c}\text { No. with nasal } \\
\text { discharge B.I. 5 or 6 } \\
\text { Total }\end{array}$ & (\%) of Col. 2 \\
(1) Borderline & 208 & 6 & $(3)$ & nil & nil \\
(2) Early lepromatous & 295 & 158 & $(54)$ & 103 & 65 \\
$\begin{array}{l}\text { (3) Established lepromatous } \\
\text { (over 3 years history) }\end{array}$ & 295 & 103 & $(35)$ & 47 & 46 \\
$\begin{array}{l}\text { (4) Lepromatous in exacerbation, } \\
\text { including histoid }\end{array}$ & 114 & 90 & $(79)$ & 79 & 88 \\
(5) Lepromatous in ENL & 24 & 6 & $(25)$ & nil & nil \\
$\quad$ Total & 936 & 363 & $(39)$ & 229 & $(23)$ \\
\hline
\end{tabular}

TABLE 2

Bacteriological comparison between nasal discharge and routine skin smears

\begin{tabular}{|c|c|c|c|c|c|c|c|}
\hline \multirow[b]{2}{*}{ Clinical group } & \multirow{2}{*}{$\begin{array}{l}\text { Patients } \\
\text { with } \\
\text { Bact. +ve } \\
\text { nose-blows }\end{array}$} & \multicolumn{3}{|c|}{$\begin{array}{l}\text { B.I. in nose-blow } \\
\text { compared with skin }\end{array}$} & \multicolumn{3}{|c|}{$\begin{array}{l}\text { M.I. in nose-blow } \\
\text { compared with skin }\end{array}$} \\
\hline & & $\begin{array}{l}\text { Higher } \\
(\%)\end{array}$ & $\begin{array}{l}\text { Similar } \\
(\%)\end{array}$ & $\begin{array}{l}\text { Lower } \\
(\%)\end{array}$ & $\begin{array}{l}\text { Higher } \\
(\%)\end{array}$ & $\underset{(\%)}{\text { Similar }}$ & $\begin{array}{l}\text { Lower } \\
(\%)\end{array}$ \\
\hline Borderline & 6 & & \multicolumn{5}{|c|}{ numbers insignificant } \\
\hline Early lepromatous & 158 & 25 & 59 & 16 & 48 & 46 & 6 \\
\hline $\begin{array}{l}\text { Established lepromatous } \\
\text { (over } 3 \text { years history) }\end{array}$ & 103 & 8 & 51 & 41 & 29 & 60 & 11 \\
\hline $\begin{array}{l}\text { Lepromatous in } \\
\text { exacerbation, } \\
\text { including histoid }\end{array}$ & 90 & 20 & 64 & 16 & 57 & 41 & 2 \\
\hline Lepromatous in ENL & 6 & \multicolumn{6}{|c|}{ numbers insignificant } \\
\hline
\end{tabular}


The following findings command attention.

(1) Among 208 patients classified as suffering from borderline leprosy, only 6 produced a specimen of nasal discharge containing Myco. leprae, none of them highly bacilliferous. All 6 patients were in an unstable exacerbating condition.

(2) The frequency and of ten highly bacilliferous nature of nasal discharges in patients with early lepromatous leprosy is a striking and significant finding. Thus 158 (54\%) of 295 such patients, some of them in a very early stage of the disease, gave positive findings, and in $65 \%$ of these a bacterial index of 5 or 6 was encountered. The morphological index exceeded that found in skin in $48 \%$.

(3) In well established lepromatous leprosy the bacteriological importance of the nasal discharge had waned. Thus $35 \%$ of 295 patients were able to produce a nasal discharge positive for Myco. leprae, a decline of $19 \%$ as compared with early cases, and the prevalence among them of a B.I. of 5 or 6 fell from $65 \%$ to $46 \%$.

(4) On the other hand, phases of exacerbation and recrudecence were once again of great importance in relation to the nasal discharge, $90(79 \%)$ out of 114 patients in this condition producing nose-blows positive for Myco. leprae. 79, i.e. $88 \%$ of these specimens had a B.I. of 5 or 6 , the morphological index in nose-blows exceeding that in skin smears in $57 \%$.

(5) In erythema nodosum leprosum the nasal discharge was of minor importance. While 6 out of 24 patients produced positive nose-blows, the baccilli were few and granular in all cases.

(6) The exceptionally large numbers of bacilli often present, and the high values for the morphological index frequently encountered, both deserve attention. The maximal reading of 6 on the international scale is inadequate to describe a smear coloured red by enormous numbers of globi and sometimes huge aggregates of bacilli. Such appearances were not rare.

\section{PATHOLOGY}

The findings of such highly bacilliferous nasal discharges in very early cases of lepromatous leprosy was unexpected, and led to the introduction of anterior rhinoscopy as routine. The very first patient so examined was a boy of 12 years, just approaching puberty, who had noticed vague reddish patches on his skin one month previously, combined with a sensation of blocking of his right nostril. Four days previously his nose had bled a little, and it was this which prompted his mother to bring him for examination. He presented signs of lepromatous leprosy in its very earliest stages. There was however a scanty but highly bacilliferous nasal discharge, and anterior rhinoscopy, using only a nasal speculum and hand torch for illumination, immediately revealed a soft nodule on the right inferior turbinate, a far more striking lesion than anything seen in the skin. This nodule, when smeared, yielded Myco. leprae in enormous numbers, with a M.I. of $50 \%$. This patient was the first of many who presented similar appearances. A thorough investigation of the nasal mucosa in early lepromatous leprosy was clearly indicated, and as a result of the cooperation of the National Institute for Medical Research, London, the Department of Human Anatomy, Oxford University, and LEPRA, this was initiated and is still in progress, based on a subsequent series of patients to those with whom we are concerned here.

We have been unable to discover any detailed account of the nasal discharge in the literature, and as it has many points of interest, a brief description of it, as encountered among the patients in the first series, is appropriate. It may be described in three stages. 


\section{Stage 1. Development}

In its beginnings, as observed in very early lepromatous leprosy, the nasal discharge is seen as a sticky yellowish exudate quite unlike the mucous secretion encountered in coryza, and the use of the word "mucus" in relation to it can be misleading. We are not simply encountering here an enhanced activity of the mucous glands in the nose, but an exudate with high cell content, and with a marked tendency to solidify and adhere to the underlying mucosa. Crust formation takes place early. Bleeding is easily provoked by attempts to blow the nose, and a specimen of exudate as discharged into a plastic bag at this stage is likely to be scanty, with traces of blood, and some crusts. Microscopically, concentrations of macrophages are typical, with very active phagocytosis of acid-fast bacilli, clearly seen inside the macrophages, and with early globus formation. Bacilli are frequently rather slender and elongated. The exudate thus has some distinctive features.

\section{Stage 2. Efflorescence}

As the disease in the nose extends, the exudate takes on its fully developed appearance. Macroscopically it may be voluminous, up to $5 \mathrm{ml}$ or more daily. It is often not homogeneous, in parts thick and saneous, elsewhere with a muco-purulent appearance, of ten streaked with blood, and containing crusts of various sizes, often of a dark colour from changed blood. It varies considerably in amount from specimen to specimen. Some patients need to clear their noses several times a day. In others the sticky exudate is more easily retained, and clearing the nose once daily may suffice, though crusting is likely to be severe in such cases, so much so that the posterior nares can be completely blocked by a solid mass of dried exudate. The humidity of the weather and secondary infection both exert an important influence.

Microscopically, the discharge presents its own pattern. Because it is of ten not homogeneous, smears need to be taken from more than one area. Samples from areas adjacent to streaks of blood are of ten the most productive. Under the microscope, a wide range of foreign bodies such as pollens and fragments of dust may be evident. Shed epithelial cells are frequent, and in decay of ten take on a pale pink colour with Ziehl Neelsen staining. With secondary infection, and rarely in reactive conditions, polymorphonuclear leucocytes may be numerous, but the basic cell component is the macrophage, always present, and usually in large numbers.

A wide range of bacteria may be observed including the normal inhabitants of the nose, cocci, diplococci, and bacilli of various types, with occasional fungal elements. In advanced stages, bacterial flora may be enormous in both numbers and range. The essential constituent, Myco. leprae, is seen in all its characteristic features, and in untreated cases, of ten in exceedingly large numbers, with elongated and curved forms common. Every stage in their ingestion and development in macrophages may clearly be demonstrated. Because the discharge may be retained in the nose for varying periods before being expelled, the M.I. may vary widely between one part of the specimen and another, with actively developing globi in one field, decaying globi in another. Because of this we have made it our practice in the direct examination of slides from the discharge to record the upper and lower limits of the M.I. between one part of the specimen and another. 


\section{Stage 3. Decline}

The discharge tends to be most copious, and contain the largest numbers of Myço. leprae, in very active established lepromatous leprosy, shortly before ulceration of the septum has led to its perforation. With perforation, the area from which bacilli are being discharged is reduced. By this time too, the inferior turbinates, as a source of discharge, are of ten past their peak through erosion and atrophy, and the diminishing area from which the discharge is drawn tends to result in a diminished volume. At the same time, secondary infection may become important and responsible for a change in the character of the discharge, which may be either more mucoid or frankly purulent, and in the later stages offensive with much crusting, but less evidence of bleeding. The discharge may be very persistent, but with reduced content of Myco. leprae.

Nowadays the natural course of events is usually interrupted by sulphone treatment, and the discharge then rapidly diminishes in volume as does the M.I. of the bacilli contained in it. Among 12 patients in this series whose nasal discharges were recorded and examined daily, and the nose given local care, a striking diminution in the volume of the nasal discharge was apparent within six weeks in all cases on an initial dapsone dosage of $5 \mathrm{mg}$ on. alternate days during the first month, rising to $10 \mathrm{mg}$ during the second month on a rising scale. By this time the morphological index in the discharge had fallen to near zero in 10 cases, and the B.I. had fallen by more than 1 unit in the international scale in 7 cases. The same trend was generally apparent in 40 other patients under frequent observation. In 3 cases, with no improvement, dapsone resistance was later demonstrated.

\section{Bacteriological Studies}

\section{METHODS}

Detailed bacteriological studies were undertaken on the nasal discharges from 31 patients selected as representing a cross section of the various clinical groups of lepromatous patients at Victoria Hospital who had at the time of admission active disease and bacteriologically positive nasal discharges. All these studies were undertaken in London at the National Institute for Medical Research on nasal discharges collected at Dichpalli and then immediately despatched by air on wet ice to London, where they were processed within 36-54 h. From the 31 patients 11 nasal discharges were single specimens collected in plastic bags from the first early-morning nose-blow, and from 17 patients the nasal discharges were 24 h-specimens collected in plastic sputum pots. From 11 of these patients a biopsy of skin from a representative active lesion was taken at the same time and also despatched on wet ice to London. Samples of bacilli from all the nasal discharges and biopsies of skin were cultured on Loewenstein-Jensen medium and inoculated into footpads of mice using the standard methods previously described (Rees, 1964). The total content of acid-fast bacilli from each nasal-discharge specimen and skin biopsy was assessed (Hart and Rees, 1960), as was the morphological index from smears prepared from these suspensions. For the quantitative bacteriological assessments and mouse footpad inoculations of the nasal discharges the specimens were first dispersed by exposure for $15 \mathrm{~min}$ to sputolysin ( $n$-acetyl-l-cysteine as a mucolytic agent) as used for the isolation of Mycobacterium tuberculosis from sputum (Kubica et al., 1964). For culture and mouse inoculation these nasal 
specimens were decontaminated by treatment with sodium hydroxide (2\% for $20 \mathrm{~min}$ at room temperature).

These specimens of nasal discharge and biopsies of skin were used to assess the total yields of acid-fast bacilli, to identify the organism as Myco. leprae and from 3 patients to determine the dapsone sensitivity of the bacilli in mice using the standard techniques previously described (Rees, 1967).

Additional nasal discharges from 3 patients were used to determine the survival of Myco. leprae within the natural secretions. These assessments were made by comparing the infectivity of Myco. leprae following mouse footpad inoculation of bacilli isolated from freshly discharged specimens with bacilli retrieved from aliquots of the same nasal discharges allowed to dry under standardised external environmental conditions for varying periods of time.

\section{IDENTIFICATION OF MYCO. LEPRAE FROM NASAL DISCHARGES}

From all 31 nasal discharges the stained acid-fast bacilli had the morphological characteristics of $M y c o$. leprae, none of the isolates produced cultures of mycobacteria on Loewenstein-Jensen medium cultured at 30,34 , or $37^{\circ} \mathrm{C}$ and all isolates following mouse footpad inoculation multiplied and gave growth curves identical to those obtained from isolates of $M y c o$. leprae from skin lesions of patients with leprosy.

\section{TOTAL YIELDS OF MYCO. LEPRAE FROM NASAL DISCHARGES}

The data from these assessments are summarised in Table 3. Thus the 24-h collections showed a mean discharge of $2.4 \times 10^{8}$ acid-fast bacilli (range $4.1 \times 10^{5}$ $-1.5 \times 10^{9}$ ) with a mean morphological index of 12.8 (range $8-26$ ) and the single nose-blow collections showed a mean discharge of $1.1 \times 10^{8}$ acid-fast bacilli (range $1.4 \times 10^{6}-4.3 \times 10^{8}$ ) with a mean morphological index of 16.9 (range 4 29). Assuming that the morphological index is a reasonable assessment of the proportion of viable $M y c o$. leprae these figures represent an average output/day from the nose of an active lepromatous patient of 31,000,000 live organisms and an average of 19,000,000 live Myco. leprae from a single early morning specimen of nasal discharge. This data stresses the relative importance of the early morning

TABLE 3

Number of Myco. leprae (acid-fast bacilli) in nasal discharges from 31 patients with lepromatous leprosy

Single nose-blow

(17 patients) 24-h nose-blow collection (14 patients)

Number of acid-fast bacilli
Range
$1.4 \times 10^{6}-4.3 \times 10^{8}$
$4.1 \times 10^{5}-1.5 \times 10^{9}$
Mean
$1.1 \times 10^{8}$
$2.4 \times 10^{8}$

Morphological Index

Range

Mean
$4-29$

16.9
$8-16$

12.8 
nasal discharge in containing the bulk of bacilli discharged compared with the relatively meagre contribution during the rest of the day. In Table 4 is set out the total content of acid-fast bacilli in single or 24-h nasal discharges from lepromatous patients compared with the concentration of bacilli/g of tissue in their skin lesions. These data show clearly that there is a significantly higher proportion of solidly staining bacilli (morphological indices) in the nasal discharges compared with the bacilli in the skin lesions. Thus the mean morphological index of the bacilli from the nose was 16.3 (range 4 -28) compared with the skin with a mean of 9.3 (range $2-19$ ).

In 3 of the selected patients there was clear evidence from their clinical history that their current active disease had evolved as a relapse after many years of intermittent treatment with dapsone. As this history was suggestive of the emergence of dapsone resistance, bacilli from their nasal discharges and biopsies of skin were inoculated into the footpads of mice in groups of untreated and dapsone treated animals in order to determine the dapsone sensitivity of the Myco. leprae isolates. In all 3 patients the results showed that the bacilli were dapsone resistant in the skin lesions and that similarly dapsone resistant bacilli were being excreted from the nose.

\section{SURVIVAL OF MYCO. LEPRAE IN NASAL DISCHARGES}

This study was undertaken to determine the survival, and duration of survival, of Myco. leprae in nasal secretions after their discharge from the nose. Nasal discharges from 3 patients with active lepromatous leprosy and positive nasal smears were selected. A portion of each freshly obtained nasal discharge was set aside for immediate mouse footpad inoculation and the remaining nasal discharge was allowed to fall on a stone surface to replicate the every-day fate of such discharges ejected direct from the nose or indirectly in the sputum. The nasal specimens as they fell on the stone surface were freely exposed to the air in the dark and allowed to dry under the environmental temperatures and humidities defined in Table 5. Aliquots from each specimen were taken from the surface of the stone at various intervals of time from 1 to 10 days. All 3 specimens were sampled at 1 day, 2 of the specimens were sampled at 1.75 days and 3 days and 1 of the specimens sampled at day 1 was also sampled at days 7 and 10. All samples from the stone surface were dry from day 1 onwards. All the fresh samples of nasal discharges and those taken after drying from the stone surface were homogenised and inoculated at 3 acid-fast bacillary concentrations into the footpads of mice. On the basis of these data it was possible to determine the proportion of Myco.leprae surviving in dried nasal discharges compared with the viability of the bacilli in their respective fresh nasal secretions. The results of these studies are summarised in Table 5 from which it can be concluded that there is full survival of Myco. leprae in nasal discharges allowed to dry for $24 \mathrm{~h}$, and that $10 \%$ of Myco. leprae survive for 1.75 days in dried nasal discharges. With 1 exception no viable bacilli were detected in nasal discharges allowed to dry for 3, 7 or 10 days. The 1 exception was from a nasal discharge dried for 7 days, where 2/12 mice inoculated with the highest dose of bacilli showed bacillary multiplication in the footpads. On the basis of this small proportion of isolates after 7 days of drying and the fact that the same dried specimen gave no multiplication after 3 days of drying it must be concluded that there were few survivors and certainly less than $1 \%$. 
TABLE 4

Data comparing Myco. leprae (acid-fast bacilli: $A F B$ ) in the nasal discharge and skin from 11 pairs of patients with lepromatous leprosy

\begin{tabular}{cccc}
\hline \multicolumn{2}{c}{ Nasal discharge } & \multicolumn{2}{c}{ Skin biopsy } \\
Total yield of AFB & Morphological Index & Yield of AFB/g skin & Morphological Index \\
\hline $1.6 \times 10^{8}$ & $14^{a}$ & $3.5 \times 10^{7}$ & $7^{a}$ \\
$7.5 \times 10^{7}$ & 26 & $3.2 \times 10^{7}$ & 16 \\
$1.9 \times 10^{7}$ & 11 & $1.8 \times 10^{7}$ & 9 \\
$4.1 \times 10^{5}$ & $18^{a}$ & $5.5 \times 10^{8}$ & $9^{a}$ \\
$4.3 \times 10^{8}$ & 19 & $3.9 \times 10^{8}$ & 5 \\
$8.3 \times 10^{6}$ & 18 & $3.2 \times 10^{9}$ & 5 \\
$3.4 \times 10^{8}$ & $28^{a}$ & $3.1 \times 10^{8}$ & 2 \\
$5.9 \times 10^{7}$ & 19 & $2.1 \times 10^{9}$ & 9 \\
$3.0 \times 10^{6}$ & 15 & $1.5 \times 10^{8}$ & 12 \\
$1.8 \times 10^{7}$ & 4 & $7.0 \times 10^{8}$ & 9.3 \\
$3.2 \times 10^{8}$ & 8 & $2.0 \times 10^{9}$ & $9.6 \times 10^{8}$ \\
\hline
\end{tabular}

a Myco. leprae from these sites proved to be dapsone resistant in the mouse footpad test.

TABLE 5

Survival of Myco. leprae in dried nasal secretions after discharge

\begin{tabular}{ccc}
\hline $\begin{array}{c}\text { Number of nasal } \\
\text { secretions tested }\end{array}$ & $\begin{array}{c}\text { Time after discharge } \\
\text { (days) }\end{array}$ & $\begin{array}{c}\text { Survival of Myco. leprae }{ }^{a} \\
(\%)\end{array}$ \\
\hline 3 & 0 & 100 \\
3 & 1.0 & 100 \\
2 & 1.75 & 10 \\
2 & 3.0 & 0 \\
1 & 7.0 & $<1^{b}$ \\
1 & 10.0 & 0 \\
\hline
\end{tabular}

Nasal secretions allowed to dry in the dark at a mean temperature of $20.6^{\circ} \mathrm{C}\left(19.8 \times 21.8^{\circ} \mathrm{C}\right)$ and mean humidity of $43.7 \%$ (35 - 47).

${ }^{a}$ Assessed as infectivity in the footpads of mice.

${ }^{b}$ Growth of Myco. leprae obtained in only 2 of 12 footpads.

\section{Discussion}

The application of quantitative bacteriological assessments of acid-fast bacilli to nasal discharges from patients with active lepromatous leprosy and the further assessment of the identity and viability of these bacilli based on the mouse 
footpad infection, have reestablished the importance of nasal infections in the aetiology and epidemiology of leprosy.

Thus the quantitative assessments of acid-fast bacilli in nasal discharges from the present studies and similar studies recently published (Rees and Ridley, 1973; Rees and Meade, 1974) have established beyond doubt that millions of bacilli are discharged daily in nasal secretions from lepromatous patients with active and, importantly, early disease. When these millions of bacilli are being discharged from the nose the patients may well be unaware that they have leprosy and clinically they have insignificant skin lesions. Moreover, biopsies of skin from these very patients, or from patients with more advanced skin infections, frequently harbour bacilli with a lower morphological index than in their nasal discharges. From this data and the elegant studies of Pedley (1970) who has shown that relatively few, if any, bacilli are discharged from closed lesions in the skin, it is clear that the main source of Myco. leprae discharged into the environment must be from the nose and upper respiratory tract. From our current systematic studies on the bacteria in nasal discharges from 31 patients, it has been established beyond doubt that the acid-fast bacilli in the nasal discharges are not contaminating culturable mycobacteria, but from their behaviour in the mouse are indisputably identified as Myco. leprae.

Having established from these series of patients in India the very large numbers of Myco. leprae discharged within single or daily accumulations of nasal secretions, and bearing in mind the biological similarities of nasal secretions and sputum and similarities in their every-day ejection and disposal by patients with leprosy or patients with pulmonary tuberculosis, it seemed essential to know the number of Myco. tuberculosis discharged in the sputum of patients with pulmonary tuberculosis. Comparable data provided by Rees and Ridley (1973) and Rees and Meade (1974) have shown that patients with advanced pulmonary tuberculosis discharge in their sputum a similar order of Myco. tuberculoses as is discharged in nasal secretions from patients with similar order of Myco. tuberculosis as is discharged in nasal secretions from patients with active lepromatous leprosy. While these similarities in the nature of the discharges from leprosy and tuberculosis patients and their comparability in bacillary content do not justify the conclusion that the transmission of the two infections are similar, it is of interest that Rees and Meade (1974) have shown that the attack rates of leprosy and tuberculosis are very similar where figures are available for both diseases in comparable areas.

Having established beyond doubt that the large number of acid-fast bacilli in nasal secretions are Myco. leprae, that the number of Myco. leprae discharged daily from the nose is comparable to $M y c o$. tuberculosis discharged in sputum from cases with pulmonary tuberculosis, and the physiological similarity of these discharges, it was of the utmost importance to determine whether Mvco. leprae survived in nasal secretions after their discharge. This information was of the greatest importance because it has long been established that the transmission and epidemiology of the spread of tuberculosis is dependent upon the significant, and unusual survival of Myco. tuberculosis in desiccated specimens of sputum (see Caldwell, 1925). Hitherto, no studies have been undertaken to determine the survival of Myco. leprae outside the body, and particularly within natural secretions. Our data show that significant numbers of viable $M y c o$. leprae can survive in dried nasal discharges for 1 to nearly 2 days and probably very reduced numbers of viable $M y c o$. leprae may persist in these natural excretions for even 7 
days. Such information could have only been obtained with the establishment of an animal model and has been dependent upon the mouse footpad infection, since Myco. leprae has still not been cultured in vitro. However, these findings are of paramount importance, since they establish for the first time that Myco. leprae can survive for a significant time outside the body and within natural secretions. These findings in conjunction with the insignificant numbers of Myco. leprae discharged from the skin of leprosy patients provide overwhelming evidence against the current hypothesis that the transmission of leprosy is predominantly dependant upon prolonged and close skin-to-skin contact. Our data is consistent with the uniform epidemiological findings in leprosy that less than $50 \%$ of patients with leprosy can be traced to a known contact. Our findings are also consistent with the likely possibility that patients who contract leprosy may well be infected with persisting viable bacilli shed into the environment several days previously by an index case. These findings still leave the route of infection undetermined. While the similarities between tuberculosis and leprosy as outlined may well favour the nose or lung as the site of entry, they do not exclude the possibility of entry via the alimentary tract or via the skin surface. It is likely that further studies using the mouse model will play an important part in elucidating these various possibilities. Current and preliminary studies suggest that aerosols of Myco. leprae can give rise to systematic infections in mice.

The patients from whose nasal discharges these detailed bacteriological studies were made, were by no means exceptional. A tight time schedule, both for air transport, and immediate processing on arrival in Londorı, meant that specimens could be obtained and despatched to London on only one day in the week. Specimens were selected on the basis of a bacterial index of 5 or 6 and high morphological index in the nasal discharge from patients who happened to arrive early on that day, or overnight, or at most $48 \mathrm{~h}$ previously, the point being that patients could not be admitted to hospital without the promise of immediate chemotherapy and nasal care. Many suitable patients arriving on other days, thus could not be used. Clearly we are not dealing with the exceptional few. Excluding patients with borderline leprosy and those in ENL, whose nasal condition had already been transformed by chemotherapy, there were in the series as a whole 333 patients with nasal discharges positive for Myco. leprae. Among these a bacterial index of 5 or 6 in the discharge was encountered in 208, or $60 \%$ on first arrival, and in most of them, this was the second specimen of the day. As proved in the material sent to London, the early morning specimen, as in tuberculosis, was the greatest in importance. There can be no reasonable doubt that the discharge of large numbers of viable Myco. leprae from the nose is a general attribute of untreated lepromatous leprosy.

The relation of the nasal discharge to clinical type and stage of the disease has several points of interest. Contrary to traditional beliefs, the heavy involvement of the nose reflected in the nasal discharge is not something which develops gradually as lepromatous leprosy progresses. Its relationship is not with the length of history of the lepromatous condition, but with its degree of activity.

The presence of a highly bacilliferous nasal discharge in early lepromatous leprosy is of particular interest and importance. In this series, patients in whom lepromatous leprosy arose as a degeneration from an earlier borderline condition were distinguished from those in whom the lepromatous type appeared from the start, but in both groups the onset of clinical lepromatous leprosy was associated very quickly with, and in some cases preceded by, symptoms of nasal involvement 
with discharge. Very often the external appearance of the nose and face gave no clue to the severity of the condition in the nasal mucosa.

In fully developed lepromatous leprosy, gross pathological changes in the nose, secondary infection, and the effects of even intermittent chemotherapy, combine to reduce the importance of the nasal discharge, which tends to be reduced both in amount and in bacillary content, both where bacterial and morphological indices are concerned. Nevertheless, the discharge is persistent, and it once again assumes great importance as soon as there are signs of exacerbation or recrudescence, when a voluminous discharge of exceedingly high bacillary content may be encountered, notably in patients with the histoid type of the disease.

The extraordinary sensitivity of Myco. leprae in the nose to even small doses of dapsone was well brought out in this study. The nasal discharge can diminish very greatly in volume and bacillary content within a few weeks, well before clinical improvement in the skin condition is apparent. The nasal discharge is thus a quite sensitive guide as to whether dapsone is being taken or not. The absence of a bacilliferous nasal discharge in a patient with active lepromatous leprosy as a rule admits of only two interpretations. Either chemotherapy has been taken in the recent past, whatever the patient may say, or the nose is blocked with hard encrusted exudate. A copious bacilli laden discharge in a patient with active lepromatous leprosy likewise has two interpretations. In general, it is strong evidence that dapsone has not been taken. In rare circumstances, in a patient with a long history of chemotherapy, it may be indicative of exacerbation with sulphone resistant organisms.

The striking difference between the findings in early lepromatous leprosy and those in borderline leprosy is another matter of great interest. The rarity of a bacilliferous nasal discharge in borderline leprosy in our series is entirely in line with the findings of Pedley (1973a), and is in marked contrast with the frequency and severity of the infection in the nose in very early lepromatous leprosy. Clearly, the nasal mucosa reflects in a very sensitive way, the immunological competence of the body as a whole. Where this is congenitally lacking, or is depressed for any reason, the nasal mucosa becomes a highly significant site of predilection for Myco. leprae, where the bacillus is able to establish itself and multiply more intensively than in the skin.

\section{Acknowledgements}

We are indebted to the British Leprosy Relief Association (LEPRA) for a grant to cover the cost of shipment by air of the specimens, and to the World Health Organization Regional Office for South East Asia for facilitating their prompt despatch. Deep appreciation is also due to many members of the staff at Victoria Hospital, Dichpalli, without whose unfailing interest and cooperation, these studies would have been impossible.

\section{References}

Barton, R. P. E. (1974). A clinical study of the nose in lepromatous leprosy. Lepr. Rev. 45 (2), 135.

Barton, R. P. E., Davey, T. F., McDougall, A. C., Rees, R. J. W. and Weddell, A. G. M. (1973). Clinical and histological studies of the nose in early lepromatous leprosy. Abstracts of Tenth International Leprosy Congress, Bergen, p. 30.

Caldwell, M. E. (1925). Viability of Mycobacterium tuberculosis in a semi-arid environment. $J$. Inf. Dis. 37, 465. 
Davey, T. F. and Rees, R. J. W. (1973). The nasal discharge in leprosy. A bstracts of Tenth International Leprosy Congress, Bergen, p. 30.

Gerber, O. P. (1901). Quoted by Klingmuller, V. (1930) Die Lepra, p. 351.

Hart, P. D'Arcy and Rees, R. J. W. (1960). Effect of Macrocyclon on acute and chronic pulmonary tuberculosis in mice as shown by viable and total bacterial counts. Brit. J. Exp. Path, 41, 414.

Jeanselme, E. and Laurens (1897a). Des localizations de la lepre sur le nez, la gorge, at le larynx. First International Leprosy Congress, Berlin, I, Part 2, p. 19.

Jeanselme, E. and Laurens (1897b) First International Leprosy Congress, Berlin, p. 22.

Klingmuller, V. (1930). Die Lepra, p. 252.

Kubica, G. P., Kaufmann, A. J. and Dye, W. E. (1964). Comments on the use of the new mucolytic agent, $N$-acetyl- $L$-cysteine as a sputum digestant for the isolation of mycobacteria. Amer. Rev. Resp. Dis. 89, 284.

Muir, E. (1929). Leprosy, Diagnosis, Treatment and Prevention. Indian Council of B.E.L.R.A., 5 th Ed, p. 53.

Pedley, J. C. (1970). Composite skin smears. Lepr. Rev. 41, 31.

Pedley, J. C. (1973a). The nasal mucus in leprosy. Lepr. Rev. 44, 33.

Pedley, J. C. (1973b). The nasal mucus in leprosy. Abstracts of Tenth International Leprosy Congress, Bergen, p. 29.

Rees, R. J. W. (1964). Limited multiplication of acid-fast bacilli in the foot-pads of mice inoculated with Mycobacterium leprae. Brit. J. exp. Path. 45, 207.

Rees, R. J. W. (1967). Drug resistance of Mycobacterium leprae, particularly to DDS. Int. J. Lepr. 35, (2), 625.

Rees, R. J. W. and Meade, T. W. (1974). Comparison of the modes of spread and the incidence of tuberculosis and leprosy. Lancet i, 47.

Rees, R. J. W. and Ridley, D. S. (1973). Bacteriology and pathology of leprosy. In Recent Advances in Clinical Pathology Series 6, 1973. (S. C. Dyke, Ed.) Edinburgh and London: Churchill Livingstone.

Rogers, L. and Muir, E. (1946). Leprosy, 3rdEd., p. 32.

Schäffer (1897). First International Leprosy Congress, Berlin, II, 62.

Schäffer (1898). On the spread of leprosy bacilli from the upper parts of the respiratory tract. Arch. Dermat. Syphil. XLIV, 159

Shepard, C. C. (1962). The nasal excretion of Myco. leprae in leprosy. Int. J. Lepr., 30, 10.

Sticker, G. (1897). Thesen uber die Pathogenese der Lepra. First International Leprosy Congress, Berlin, I, pp. 99-100. 